\title{
Effects of a Mixed Zone on TGO Displacement Instabilities of Thermal Barrier Coatings at High Temperature in Gas-Cooled Fast Reactors
}

\author{
Jian Wang, ${ }^{1}$ Jun Ding, ${ }^{1,2}$ Kun Song, ${ }^{1}$ Song Chen, ${ }^{1}$ and Xia Huang ${ }^{1}$ \\ ${ }^{1}$ College of Mechanical Engineering, Chongqing University of Technology, Chongqing 400054, China \\ ${ }^{2}$ Key Laboratory of Manufacture and Test Techniques for Automobile Parts, Ministry of Education, Chongqing 400054, China
}

Correspondence should be addressed to Xia Huang; huangxia@cqut.edu.cn

Received 1 June 2016; Revised 20 September 2016; Accepted 4 October 2016

Academic Editor: Michel Giot

Copyright (C) 2016 Jian Wang et al. This is an open access article distributed under the Creative Commons Attribution License, which permits unrestricted use, distribution, and reproduction in any medium, provided the original work is properly cited.

\begin{abstract}
Thermally grown oxide (TGO), commonly pure $\alpha-\mathrm{Al}_{2} \mathrm{O}_{3}$, formed on protective coatings acts as an insulation barrier shielding cooled reactors from high temperatures in nuclear energy systems. Mixed zone (MZ) oxide often grows at the interface between the alumina layer and top coat in thermal barrier coatings (TBCs) at high temperature dwell times accompanied by the formation of alumina. The newly formed MZ destroys interface integrity and significantly affects the displacement instabilities of TGO. In this work, a finite element model based on material property changes was constructed to investigate the effects of $M Z$ on the displacement instabilities of TGO. MZ formation was simulated by gradually changing the metal material properties into MZ upon thermal cycling. Quantitative data show that MZ formation induces an enormous stress in TGO, resulting in a sharp change of displacement compared to the alumina layer. The displacement instability increases with an increase in the MZ growth rate, growth strain, and thickness. Thus, the formation of a MZ accelerates the failure of TBCs, which is in agreement with previous experimental observations. These results provide data for the understanding of TBC failure mechanisms associated with MZ formation and of how to prolong TBC working life.
\end{abstract}

\section{Introduction}

A new concept in nuclear energy systems, known as Generation IV, was proposed to meet future energy needs during the Generation IV International Forum in 2012. Generation IV nuclear reactors have a number of advantages compared to presently used nuclear reactors, including greater safety, dependability, durability, cost, and nonproliferation, and could help eliminate the use of plutonium and eventually lead to nuclear disarmament [1]. The Gas-Cooled Fast Reactor is one of the most researched concepts of Generation IV. It uses helium as a coolant and usually works under thermal cycle conditions with an external temperature of $850^{\circ} \mathrm{C}$, which could even increase to a maximum of $1250^{\circ} \mathrm{C}$. The ceramic materials used in the Gas-Cooled Fast Reactor must possess a high heat resistance, density, and thermal conductivity in order to protect the helium turbine components from high temperatures. Further, these ceramics should be corrosion resistant against a helium gas flow at speeds of $280 \mathrm{~m} / \mathrm{s}$
[2]. thermal barrier coatings (TBCs) have therefore been proposed as suitable protective coatings, offering thermal insulation, heat resistance, and corrosion resistance.

A typical TBC system usually consists of four components: (1) the ceramic top coat, (2) the bond coat (BC), (3) the thermally grown oxide (TGO), and (4) the metal substrate $[3,4]$. The fast development of advanced engines has led to an increase in working temperatures, resulting in increased requirements from substrate materials; however, advances in substrate materials can hardly keep pace with the increase in demands. Therefore, the use of TBCs for thermal insulation is both convenient and efficient. TBCs play an important role in the thermal protection of the substrate components, since they are able to offer a temperature differential of up to $300^{\circ} \mathrm{C}$ [5]. As a result, various studies have been performed worldwide regarding the failure mechanisms and lifespan of TBCs.

The performance and durability of TBCs are controlled by both internal (i.e., sintering effects and residual stresses) 
and external (i.e., actual service conditions such as calcium magnesium alumina-silicate attack, erosion, impact damage, and countermeasures [6]) factors. Karlsson and Evans [7] found that TGO was the main factor leading to TBC failure. In their studies, they developed three-layer TBCs without a ceramic layer to assess the instabilities caused by TGO growth and found that the constituent properties had a major influence on the instabilities. The growth of TGO at elevated temperatures can lead to a large compressive stress of up to 3 to $6 \mathrm{GPa}$ [4]. Hsueh and Fuller [8] revealed the analytical expression of TGO growth stress in light of elastic-plastic mechanics and Euler beam theory, which predicted the stress field in each layer. Ding et al. [9] investigated the displacement instability of TGO through a novel quantitative method which could model TGO growth without the limitation of TGO thickness. Their work shows a good agreement with experimental observations, even at TGO thicknesses of up to $5 \mu \mathrm{m}$.

However, all of the above mentioned studies considered the TGO material in TBCs as a pure alumina layer, namely, $\mathrm{Al}_{2} \mathrm{O}_{3}$. Nevertheless, a TGO layer is usually composed of various oxide phases such as $\mathrm{NiAl}_{2} \mathrm{O}_{4}, \mathrm{NiO}$, and $\mathrm{Cr}_{2} \mathrm{O}_{3}$. The outward aluminum diffusion and uptake of zirconia will lead to the formation of a $(\mathrm{Al}, \mathrm{Cr})_{2} \mathrm{O}_{3}$ mixed zone (MZ). Liu et al. [10] studied the microstructural evolution at the interfaces of TBCs by transmission electron microscopy during isothermal oxidation and found that the TGO layer would split into two sublayers, one of which consists of a mixture of $\alpha-\mathrm{Al}_{2} \mathrm{O}_{3}$, $\mathrm{Cr}_{2} \mathrm{O}_{3}$, and $\mathrm{Ni}(\mathrm{Al}, \mathrm{Cr})_{2} \mathrm{O}_{4}$ and the other of dense $\mathrm{Al}_{2} \mathrm{O}_{3}$ and $\mathrm{Cr}_{2} \mathrm{O}_{3}$. Their work helps clarify the failure mechanism due to microstructural changes caused by chemical reactions between the related elements. Hernandez et al. [11] studied TGO creep and the initiation of a class of fatigue cracks in TBCs using a thermal gradient mechanical fatigue test. In their study, they considered the MZ as a part of TGO layer and examined and quantified the thermomechanical performance of TGO through a finite element (FE) modelling method. Their results indicated that the stress-redistribution caused by creep can result in tensile stress in the TGO and that the stress was large enough to initiate cracks. Lv et al. [12] adopted a spherical shell model to investigate the effects of sintering and mixed oxide (MO) growth on interface cracking of TBCs at high temperatures and concluded that the smaller growth rate of MOs would delay interface cracking. Xu et al. [13] studied the interfacial fracture mechanism associated with MO growth in TBCs and found that MO plays an important role on interface integrity; high growth rates of $\mathrm{MO}$ and high coverage of MO would both accelerate the initiation and propagation of interface cracks. Braue et al. [14, 15] investigated the microstructural evolution of an aluminazirconia MZ in a TBC system using analytical electron microscopy to investigate the instability of the MZ/TBC interface. Their experiments showed that the growth of a MZ occurred in three stages, namely, the formation of MZ during TBC spraying, followed by a constant $\mathrm{MZ}$ composition due to $\alpha-\mathrm{Al}_{2} \mathrm{O}_{3}$ densification, and resumed growth due to destabilization of TBCs. Nevertheless, these experimental results hardly reflect the real case scenario of TBCs under their extreme service conditions. Review of previous studies shows that few have addressed the simulation of MZ formation and therefore the effects of this on the durability and performance of TBCs remain unknown.

Herein, the effects of MZ formation on the displacement instabilities of TGO have been investigated through a FE model. The thermal cycle growth of a four-component (alumina-MZ-alumina-MZ) TGO layer was simulated with the USDFLD and UEXPAN user subroutines in ABAQUS. $M Z$ growth rate, growth strain, and thickness were studied to assess the influence of MZ on TGO displacement instabilities. The simulation results indicated that a MZ would cause a drastic change of displacement compared with the alumina layer and induced an enormous stress in TGO. An increase in $\mathrm{MZ}$ growth rate, growth strain, and thickness would lead to an increase in TGO displacement instabilities. On the other hand, a MZ might accelerate TBC failure. The results of this study reveal that the degradation mechanism of TBCs is related to $\mathrm{MZ}$ formation and can be used as a reference to improve the durability of and extend the service life of TBCs.

\section{Finite Element Model}

2.1. Geometry and Model Description. In order to investigate the displacement instability of TGO due to the formation of a MZ, a two-dimensional plane model was established as shown in Figure 1. The simplified TBC model takes into account three layers, namely, the TGO layer, a BC, and the super alloy substrate. The TGO layer is divided into two sublayers: an alumina layer adjacent to the $\mathrm{BC}$ and a $\mathrm{MZ}$ above it [11]. An initial alumina layer and an initial $\mathrm{MZ}$ layer are constructed to model oxidation during the spraying process. The periodic boundary condition is imposed on the FE model to simulate the random existence of the imperfections in TBC system. The command EQUATION in ABAQUS is used to impose $x$ displacement in horizontal axis in order to keep the same displacement in $x$ direction for the nodes on the right side. The same method is used to constrain the $y$ displacement of the nodes at the bottom side to avoid the bending deformation induced by thermal expansion during the period of cooling and reheating. The first-order generalized plane strain elements, CPEG4 in ABAQUS software, are used to construct the FE model, and the number of elements is checked by the dependency of mesh. Each thermal cycle consisted of three steps: a $600 \mathrm{~s}$ cooling down from $1200^{\circ} \mathrm{C}$ to ambient temperature, heating to the highest temperature in $600 \mathrm{~s}$, and holding of this temperature for $1800 \mathrm{~s}$. Table 1 displays the material property configuration for the FE model.

2.2. TGO Growth. TGO usually forms during high temperature service conditions. The inward diffusion of oxidants and outward diffusion of aluminum leads to a reaction zone on the top coat/BC interface. The chemical reaction can be displayed as $4 \mathrm{Al}+3 \mathrm{O}_{2} \rightarrow 2 \mathrm{Al}_{2} \mathrm{O}_{3}$. When diffused $\mathrm{Ni}$ and $\mathrm{Cr}$ from the $\mathrm{BC}$ react with $\mathrm{O}, \mathrm{MZ}$ growth commences. The formation of $\mathrm{MZ}$ can be indicated by $[\mathrm{Ni}]+\alpha-\mathrm{Al}_{2} \mathrm{O}_{3}+$ $\mathrm{Cr}_{2} \mathrm{O}_{3}+[\mathrm{O}] \rightarrow \mathrm{Ni}(\mathrm{Al}, \mathrm{Cr})_{2} \mathrm{O}_{4}$. An initial TGO layer usually forms during the manufacturing stage and the newly formed TGO usually has a columnar grain structure. As shown in 


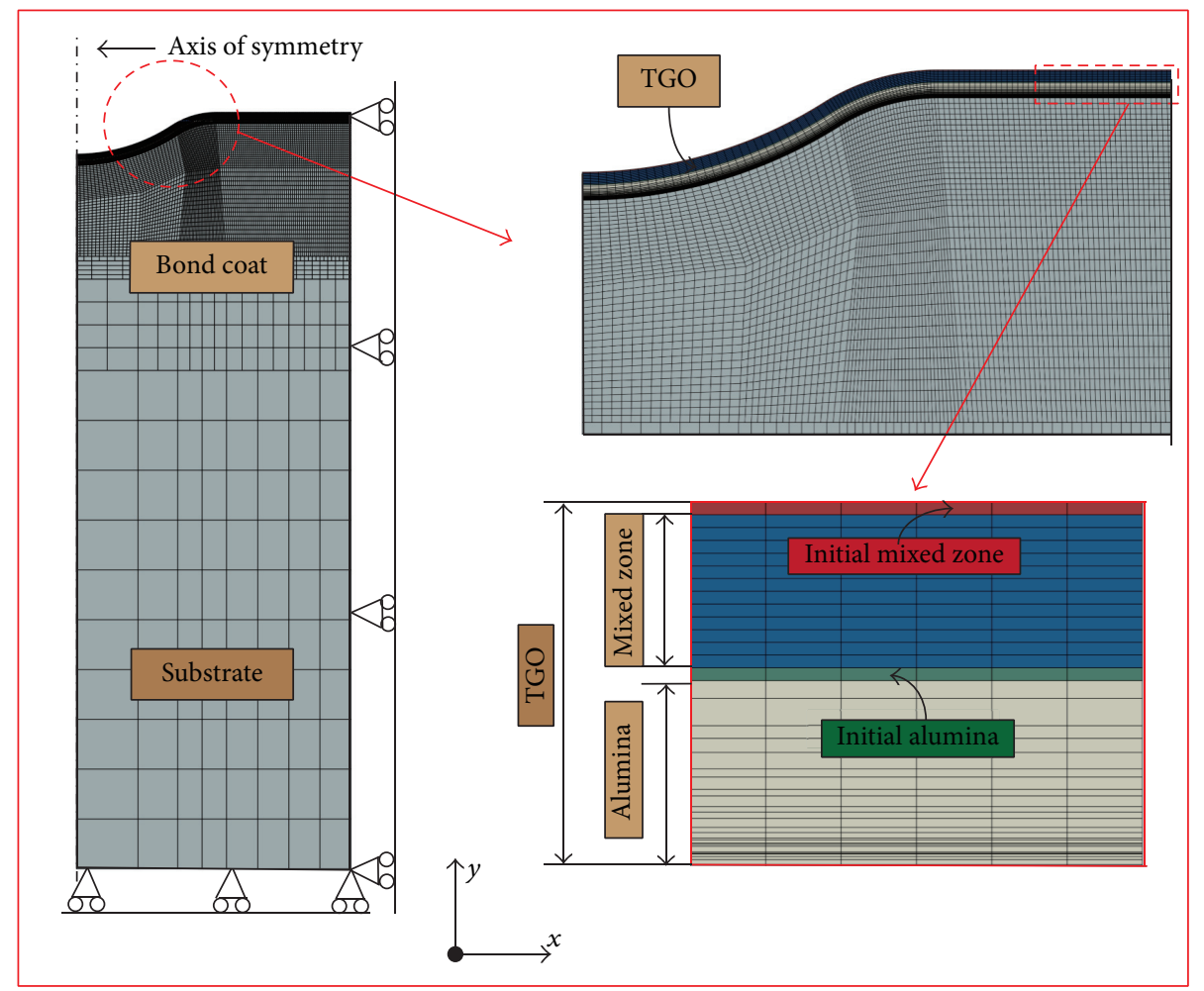

FIGURE 1: The geometry and boundary conditions used in the FE model analysis.

TABle 1: Material property configuration for the finite element model.

\begin{tabular}{lcccc}
\hline Material property & Substrate & $\begin{array}{c}\text { Bond } \\
\text { coat }\end{array}$ & Alumina & $\begin{array}{c}\text { Mixed } \\
\text { zone [13] }\end{array}$ \\
\hline $\begin{array}{l}\text { Elastic modulus, } E \\
(\mathrm{GPa})\end{array}$ & 140 & 140 & 390 & 100 \\
$\begin{array}{l}\text { Poisson ratio, } v \\
\begin{array}{l}\text { Thermal expansion } \\
\text { coefficient, } \alpha\left(10^{-6}\right)\end{array}\end{array}$ & 0.3 & 0.3 & 0.2 & 0.3 \\
\hline
\end{tabular}

Figure 2, the reactions at the grain boundary gaps result in an increase in TGO length, while the TGO formed at the TGO/BC interface leads to thickening of the TGO layer. As a result, TGO grows in two directions, lateral growth and normal growth, during thermal cycling. Consequently, the growth strain of TGO is considered as two components: $\varepsilon_{t}$ and $\varepsilon_{g}$, where $\varepsilon_{t}$ is normal growth strain on the TGO/BC interface and $\varepsilon_{g}$ is the lateral growth strain parallel to the interface. The growth of TGO can be divided into three stages, as in previous experimental observations [14, 15]. The MZ forms during the initial thermal exposure stage and remains at this thickness for a considerable time due to the formation of a dense $\alpha-\mathrm{Al}_{2} \mathrm{O}_{3}$ layer preventing the outward diffusion of $\mathrm{Cr}$ and $\mathrm{Ni}$ anions, while in the late stage, the outward diffusion of $\mathrm{Cr}$ and $\mathrm{Ni}$ from the $\mathrm{BC}$ induces $\mathrm{MZ}$ growth.

2.3. The Numerical Simulation Procedure. The simulation procedure of TGO growth is shown in Figure 3. The red layer represents the initial $\mathrm{MZ}$ whilst the green layer represents the initial alumina layer. The dark blue layers, composed of 12 sub-layers of equal thickness due to the constant growth rate at long time intervals as experimentally observed [16, 17], represent the $\mathrm{MZ}$, with a total thickness of $2 \mu \mathrm{m}$. The light brown layers represent the alumina layers, with 24 sublayers of varying thicknesses since alumina layer growth usually follows a parabolic line [4]. The simulation of TGO growth was divided into three stages to match previous experimental observations $[14,15]$. Firstly, the initial alumina and MZ layers were assigned a material property each and the subsequent alumina and MZ layers were assigned a BC material property. Secondly, the 24 alumina thickening sublayers transformed into alumina layers from top to down during 24 thermal cycles. Thirdly, the $12 \mathrm{MZ}$ sublayers began to turn into the material property of MZ upon varying thermal cycles to study the effect of MZ growth rate.

The alumina layer grows at a relatively slow rate compared with that of MZ. A number of experiments had found that the $M Z$ growth rate is usually several times faster than that of alumina $[14,18]$. Herein, we adopted the user subroutine USDFLD in ABAQUS to simulate the thickening of TGO, as in previous studies [9]. As for the lateral growth strain, the magnitude of the alumina growth strain, $\varepsilon_{\mathrm{Al}}$, ranges from $10^{-4}$ to $5 \times 10^{-3}$ as shown by experimental observations, while the normal growth strain of alumina is usually one-tenth that of the alumina lateral growth strain [7]. When it comes to $\mathrm{MZ}$, the normal growth strain usually equals lateral growth strain $[12,13]$. What is more, MZ usually grows several dozen times of alumina [14]. In this work, we selected $\varepsilon_{\mathrm{Al}}=2.4 \times 10^{-3}$ as indicated by $\mathrm{Xu}$ et al. [13]. The lateral growth strain, $\varepsilon_{m}$, of 


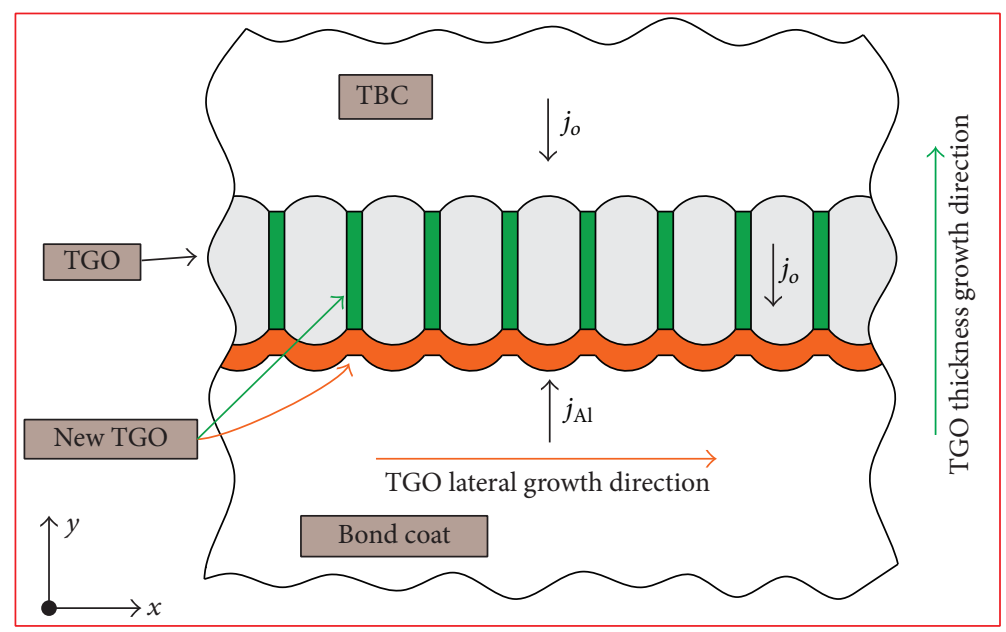

FIgUre 2: A schematic of TGO growth phenomena.

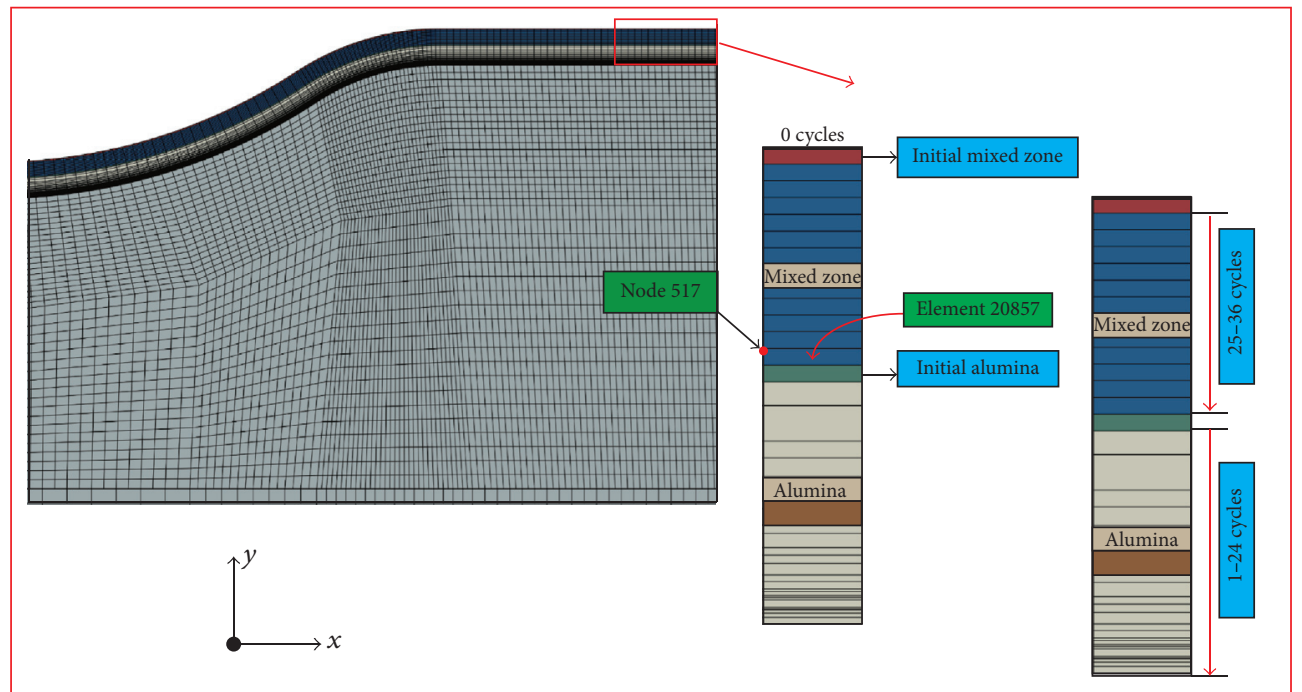

FIGURE 3: TGO thickening simulated by USDFLD in ABAQUS.

$\mathrm{MZ}$ was set as $\varepsilon_{m}=2.4 \times 10^{-2}, \varepsilon_{m}=4.8 \times 10^{-2}$, and $\varepsilon_{m}=$ $7.2 \times 10^{-2}$, which were 10,20 , and 30 times larger than $\varepsilon_{\mathrm{Al}}$, respectively. During the simulation, the lateral growth strains were applied at high temperature period of each thermal cycle through user subroutine UEXPAN in ABAQUS, and no lateral growth strain was imposed at the cooling and reheating stages. The different lateral growth strains were implemented by user code in UEXPAN. The incremental thermal strains are applied to the corresponding elements during each thermal cycle to realize the lateral growth of alumina and MZ. For MZ thickness growth, the thickening strain is assumed equal to $\mathrm{MZ}$ lateral growth strain [13]. However, we used the material change method, as in our previous work [9], instead of MZ thickening strain. To study the effects of MZ thickness growth rate, MZ layers formed during each thermal cycle were assigned as one layer for each thermal cycle, two layers for each thermal cycle, three layers for each thermal cycle, and four layers for each thermal cycle. Thus, the thickness growth rate equals $v_{1}=0.2 \times 10^{-3} \mathrm{~mm} / \mathrm{h}$, $v_{2}=0.4 \times 10^{-3} \mathrm{~mm} / \mathrm{h}, v_{3}=0.6 \times 10^{-3} \mathrm{~mm} / \mathrm{h}$, and $v_{4}=$ $0.8 \times 10^{-3} \mathrm{~mm} / \mathrm{h}$ when translating $\mathrm{MZ}$ formation during each thermal cycle into millimeters per hour. The specific research protocols were shown in Table 2 . Analyses $1-4,5-8$, and 9-12 aimed to study the effect of MZ thickness growth rate on the displacement instability of TGO. Analyses 1, 5, and 9, 2, 6, and $10,3,7$, and 11 , and 4,8 , and 12 were set to investigate the effect of lateral growth strain on TGO displacement instability.

\section{Results and Discussion}

3.1. Effects of Mixed Zone Thickness Growth Rate. Previous studies assessing the displacement instability caused by TGO have usually regarded the TGO phase as a pure alumina layer. However, the TGO is mainly dense and uniform $\alpha-\mathrm{Al}_{2} \mathrm{O}_{3}$ in the early stage of TBCs, then transforming to a $\mathrm{MZ}$ due to the depletion of aluminum $[10,14,17]$. The MZ is usually located between the top coat and the alumina layer $[15,18]$. Herein, we established FE models with various MZ growth rates for 


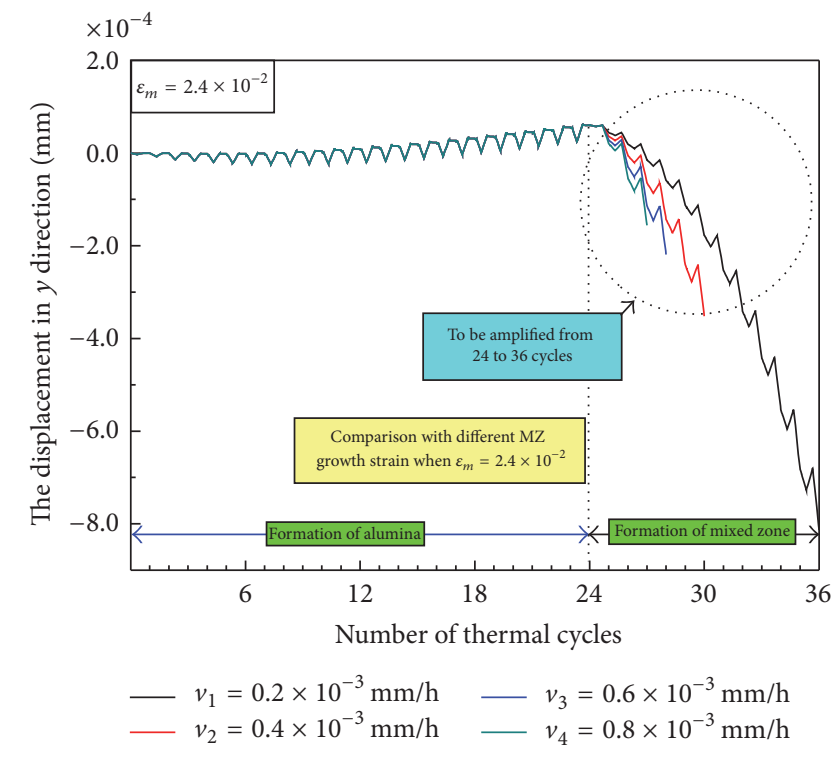

(a)

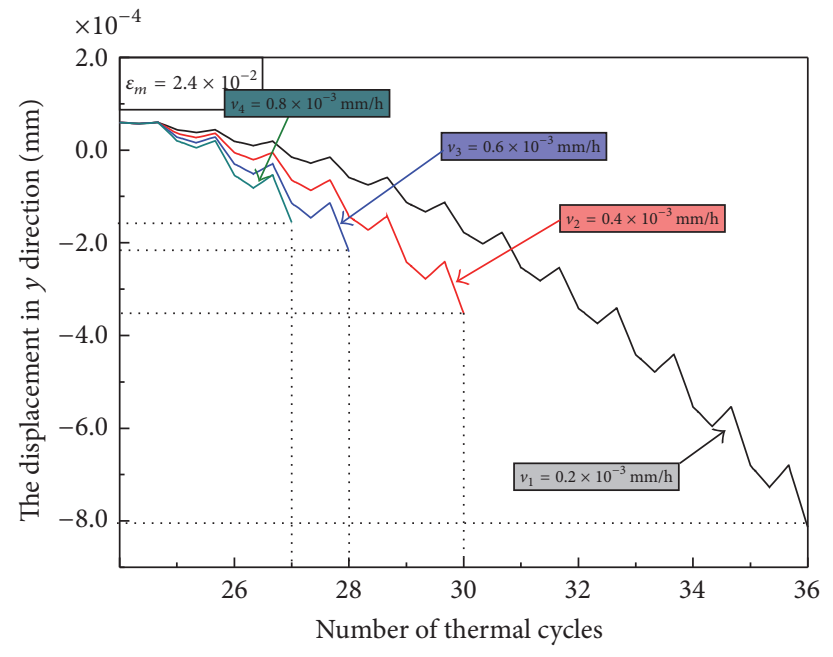

(b)

FIGURE 4: (a) The plot of displacement in $y$ direction for node number 517 at the base of the surface groove against the number of thermal cycles when $\varepsilon_{m}=2.4 \times 10^{-2}$. (b) The details for the variation of displacement for the formation of MZ.

TABLE 2: Research protocols used in this paper.

\begin{tabular}{lccc}
\hline Analysis & Element & $\begin{array}{c}\text { Lateral growth } \\
\text { strain, } \varepsilon_{m}\end{array}$ & $\begin{array}{c}\text { Mixed zone growth rate, } \\
v(\mathrm{~mm} / \mathrm{h})\end{array}$ \\
\hline 1 & & 0.2 \\
2 & 0.024 & 0.4 \\
3 & & 0.6 \\
4 & & 0.8 \\
5 & & & 0.2 \\
6 & CPEG4 & 0.048 & 0.4 \\
7 & & & 0.6 \\
8 & & & 0.8 \\
9 & & & 0.2 \\
10 & & & 0.4 \\
11 & 0.072 & 0.6 \\
12 & & 0.8 \\
\hline
\end{tabular}

the purpose of studying the influences of MZ growth rate on the displacement instability of TGO.

Figure 4(a) shows the effects of MZ on TGO displacement for the node number 517 in the $y$ direction under various growth rates. In both cases the TGO undergoes the same lateral growth strain $\left(\varepsilon_{m}=2.4 \times 10^{-2}\right)$, and it may therefore be concluded that the displacement instability of TGO occurs in two stages. Firstly, displacement gradually changes during the first 24 thermal cycles, with the TGO phase being mainly alumina, in agreement with experimental observations. Secondly, the displacement drops rapidly at the beginning of the 25th thermal cycle, thus caused by MZ formation. It is obvious that the formation of the MZ played a greater role in the displacement instability as compared to the alumina. When the MZ was investigated separately (Figure 4(b)) to

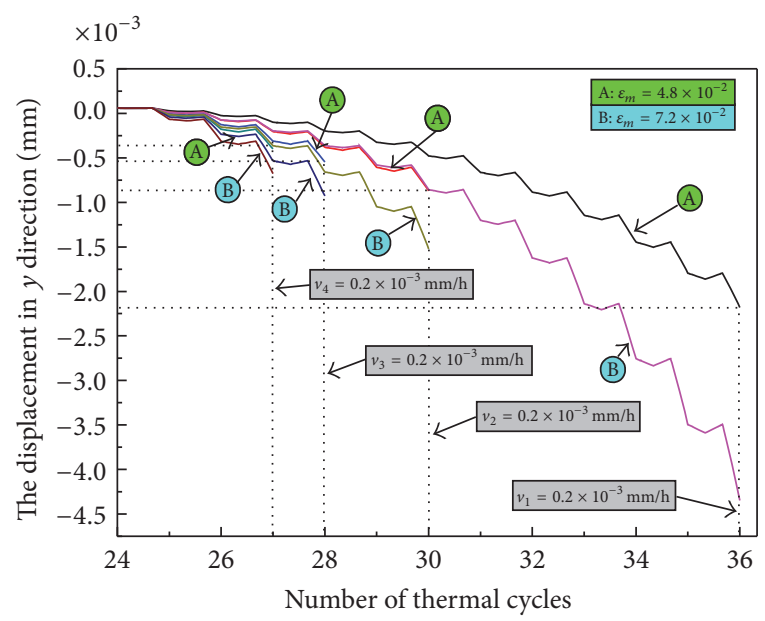

FIGURE 5: The plot of displacement in $y$ direction for node number 517 at the base of the surface groove against the number of thermal cycles when $\varepsilon_{m}=4.8 \times 10^{-2}, \varepsilon_{m}=7.2 \times 10^{-2}$.

study the effects of MZ growth rate, TGO displacement increased with an increase in $\mathrm{MZ}$ growth rate. As $\mathrm{MZ}$ thickness remained constant, the cyclic numbers decreased with the increasing $\mathrm{MZ}$ growth rate. Therefore, for the $\mathrm{FE}$ model, when $v_{1}=0.2 \times 10^{-3} \mathrm{~mm} / \mathrm{h}$, it had the largest cyclic numbers and the displacement was nearly $0.8 \mu \mathrm{m}$ which was close match with the previous experiments observations $[14,15]$. Furthermore, it also had the largest displacement at the end of the thermal cycles, since the lowest MZ growth rate had the longest oxide time, and eventually accumulated the largest displacement. The smallest displacement occurred when the growth rate was $v_{4}=0.8 \times 10^{-3} \mathrm{~mm} / \mathrm{h}$.

However, it can also be confidently concluded that the larger the MZ growth rate, the larger the change in TGO displacement rate. Indeed, Figure 5 shows that when the 


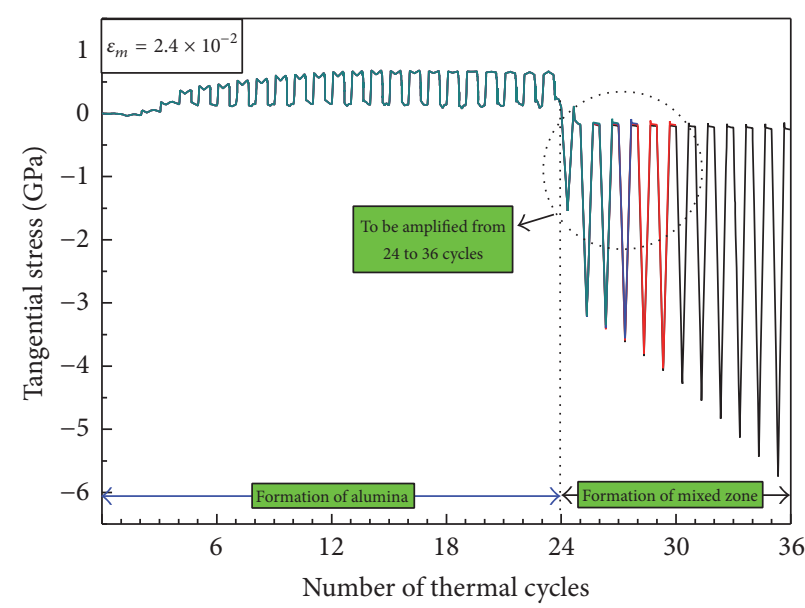

$-v_{1}=0.2 \times 10^{-3} \mathrm{~mm} / \mathrm{h} \quad-v_{3}=0.6 \times 10^{-3} \mathrm{~mm} / \mathrm{h}$

(a)

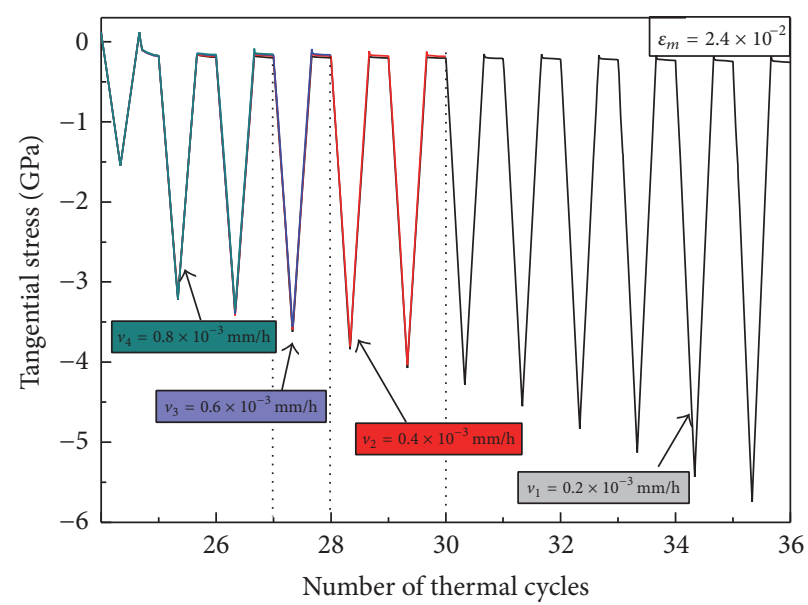

(b)

Figure 6: (a) The variation of the tangential stress at element number 20857 at the base of the surface groove against the number of thermal cycles when $\varepsilon_{m}=2.4 \times 10^{-2}$. (b) The details for the variation of tangential stress during the formation of MZ.

lateral growth strain $\varepsilon_{m}=4.8 \times 10^{-2}$, then $\varepsilon_{m}=7.2 \times$ $10^{-2}$. Further, Figure 5 also shows that the displacement fell rapidly when MZ formation began and the max displacement even reaches to more than $4 \mu \mathrm{m}$ which agrees well with the previous works finished by Braue et al. $[14,15]$. The rate of displacement increased with increasing MZ growth rate, while the final displacement decreased with increases in the MZ growth rate. Additionally, using the same growth rate but different lateral growth strain values $\left(\varepsilon_{m}=4.8 \times\right.$ $10^{-2}$ and $7.2 \times 10^{-2}$, resp.), the larger the lateral growth strain the larger the displacement. Furthermore, when the displacement instabilities were compared (Figures 4 (b) and 5), the larger the MZ growth strain, the sharper the change in displacement instability. Above all, an increase in MZ growth rate led to an increase in displacement of TGO. The higher the MZ growth rate, the higher the TGO rate in TGO displacement change but the lower the displacement at the end of the thermal cycles.

Stress plays an important role in the displacement instability of TGO. It is widely accepted that the growth of TGO will induce a huge residual stress in TBCs, which leads to the majority of TBC failures. Additionally, MZ formation can result in a severe change of stress in TGO due to its porous and nonuniform features. In other words, the TGO will suffer from higher tensile or compressive stress due to the presence of MZ. As shown in Figure 6(a), the evolution of tangential stress also followed a two-stage process, with a relatively smooth stage during alumina layer formation and a severe change stage during MZ formation. When considering the effects of MZ on stress evolution in TGO (Figure 6(b)), the largest stress of each thermal cycle is in the range of $0-6 \mathrm{GPa}$, which is in well agreement with the studies of Karlsson and Evans [7] and Evans et al. [4]. And the higher the growth rate is, the faster the stress reached its maximum value. Conversely, the lower the growth rate is (e.g., $v_{1}=$
$0.2 \times 10^{-3} \mathrm{~mm} / \mathrm{h}$ ), the slower the stress reached its maximum. However, we could not deny that the stress in TGO reaches to the largest value when $v_{1}=0.2 \times 10^{-3} \mathrm{~mm} / \mathrm{h}$ compared with the last three growth rates. Since MZ thickness remained at a constant value, the increase in MZ growth rate would induce a decrease in oxidation time, allowing for the stress to accumulate and to finally reach its maximum value. Therefore, at constant MZ thickness conditions, the slower the growth rate, the higher the tangential stress. The stress increased with a decrease in MZ growth rate.

With regard to tangential stress (Figure 7 with $\varepsilon_{m}=2.4 \times$ $10^{-2}, 4.8 \times 10^{-2}$, and $\left.7.2 \times 10^{-2}\right)$, this started to increase rapidly during MZ formation. The faster the growth rate is, the faster the tangential stress reached its maximum value. The stress of each thermal cycle is quite different and the largest stress even reaches to more than $15 \mathrm{GPa}$ which seems not to agree with the works of Karlsson and Evans. The reason is that we adopted an idealized research method to study the instabilities caused by TGO growth. And in order to study the difference caused by the parameters such as lateral growth strain, we set $\varepsilon_{m}=2.4 \times 10^{-2}, \varepsilon_{m}=4.8 \times 10^{-2}$, and $\varepsilon_{m}=7.2 \times$ $10^{-2}$. From Figure 6(b) we know that when $\varepsilon_{m}=2.4 \times 10^{-2}$ the stress is less than $6 \mathrm{GPa}$, which fits well with Karlsson's work. In other words, that means the parameters we used are suitable for the research work. Furthermore, the larger the $M Z$ growth strain, the sharper the change in displacement instability. Stress increased with an increase in growth strain, as will be discussed in Section 3.2. Overall, the higher the MZ growth rate, the higher the TGO displacement change rate, and therefore displacement instability increased with increasing MZ growth rate.

3.2. Effects of Mixed Zone Lateral Growth Strain. As shown in Figure 8, we studied the displacement instability induced by the different growth with the same growth rate 


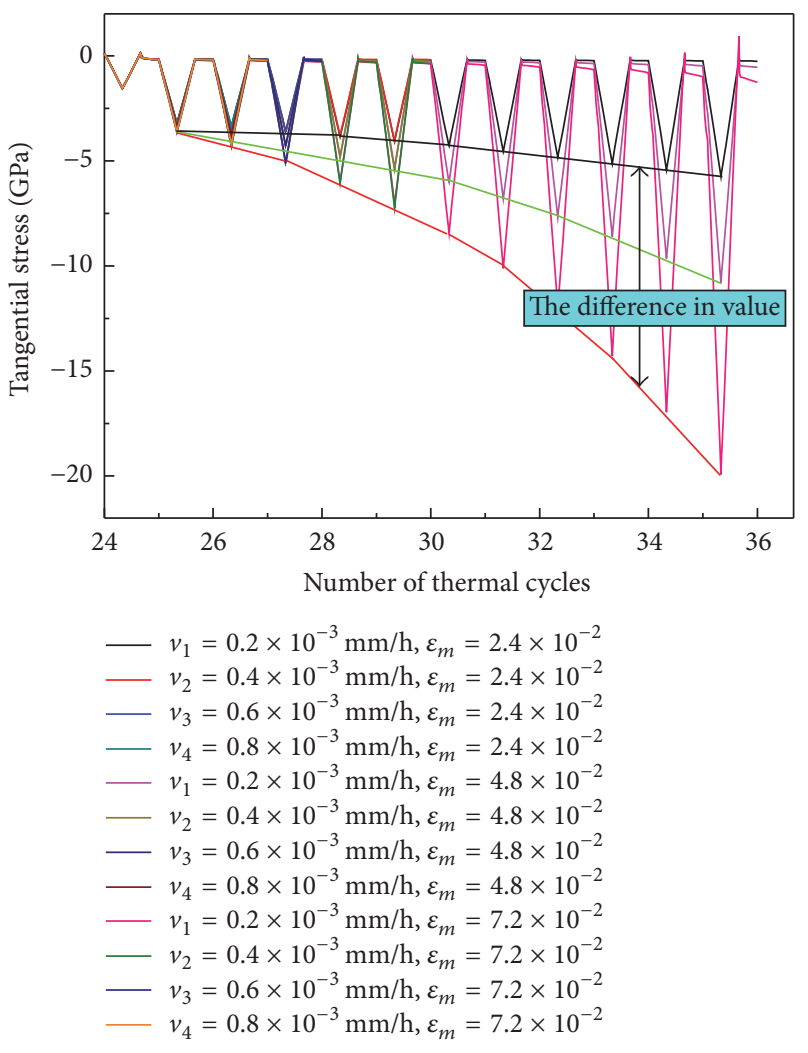

FIGURE 7: The variation of the tangential stress at element number 20857 at the base of the surface groove against the number of thermal cycles when $\varepsilon_{m}=2.4 \times 10^{-2}, \varepsilon_{m}=4.8 \times 10^{-2}$, and $\varepsilon_{m}=7.2 \times 10^{-2}$.

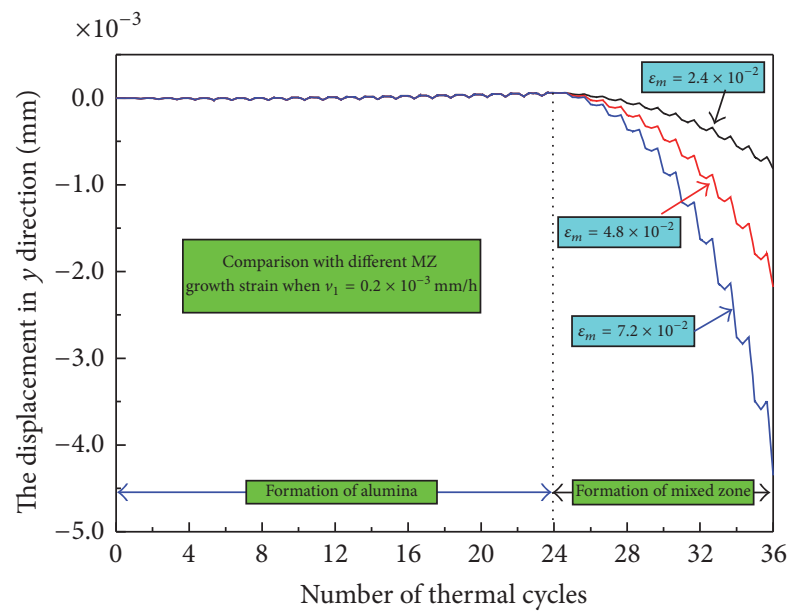

FIGURE 8: The plot of displacement in $y$ direction for node number 517 at the base of the surface groove against the number of thermal cycles when $v_{1}=0.2 \times 10^{-3} \mathrm{~mm} / \mathrm{h}$.

$\left(v_{1}=0.2 \times 10^{-3} \mathrm{~mm} / \mathrm{h}\right)$. The same two-stage process applies herein, with a slow change during the first 24 thermal cycles followed by a sharp change from the beginning of the 25th thermal cycle until the end, at which stage MZ growth began. The larger the growth strain is, the faster the displacement changed, and the larger the final displacement

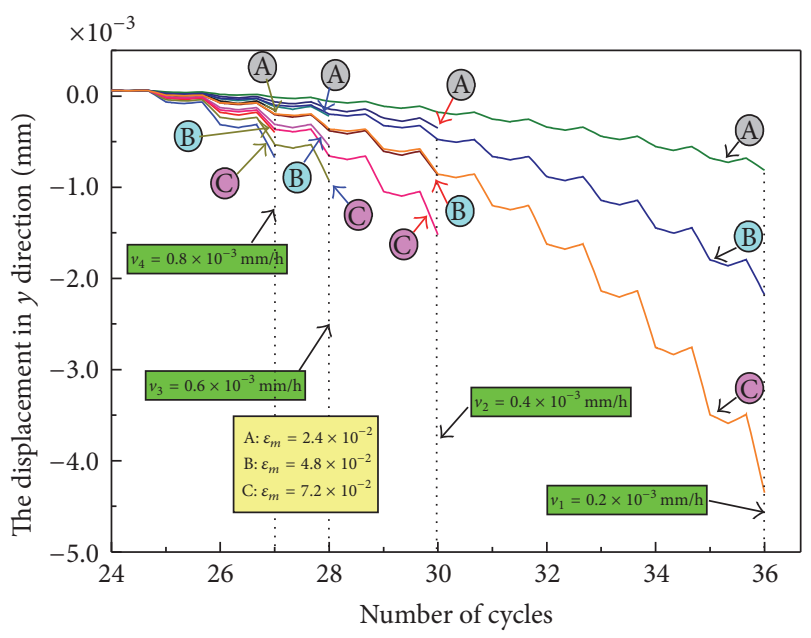

FIGURE 9: The plot of displacement in $y$ direction for node number 517 at the base of the surface groove against the number of thermal cycles with all conditions of MZ growth strain.

is. Therefore, the MZ had a greater effect on displacement instability compared to the alumina layer. Furthermore, when comparing displacement instability (Figure 9) with the $\mathrm{MZ}$ growth rates were $v_{1}=0.2 \times 10^{-3} \mathrm{~mm} / \mathrm{h}, v_{2}=0.4 \times 10^{-3} \mathrm{~mm} / \mathrm{h}$, $v_{3}=0.6 \times 10^{-3} \mathrm{~mm} / \mathrm{h}$, and $v_{4}=0.8 \times 10^{-3} \mathrm{~mm} / \mathrm{h}$, respectively. In general, the higher the growth strain, the faster the change in displacement and, finally, the larger the displacement.

Stress exhibited a rapid change during MZ formation (Figure 10(a)). Furthermore, the larger the growth strain, the larger the tangential stress. Additionally, the MZ layer had a significant influence on the evolution of stress compared to the alumina layer. In order to assess the difference between the different growth strains, we separately assessed the last 12 thermal cycles during which MZ conversion began (Figure 10(b)). The results showed that the largest stress also reaches to more than $15 \mathrm{GPa}$, which is the same reason as the explanation given for Figure 7. The larger the lateral growth strain, the higher the tangential stress for each thermal cycle, and a maximum tangential stress is reached at the end of the thermal cycle. This effect was also observed at $v_{2}=0.4 \times 10^{-3}$, $0.6 \times 10^{-3}$, and $0.8 \times 10^{-3} \mathrm{~mm} / \mathrm{h}$ (Figure 11), showing that the tangential stress increases significantly during MZ formation. Furthermore, the larger the growth strain, the larger the tangential stress under the same growth rate.

3.3. Effects of Mixed Zone Thickness. The stress and displacement instability induced by the thickness of $\mathrm{MZ}$ in TGO were analyzed. From the results in Sections 3.1 and 3.2 , the displacement instability would increase with the increase in TGO thickness. However, the thickening of the alumina layer did not induce a considerable increase in stress compared with the MZ layer. In other words, the MZ thickness had a significant influence on the displacement instability compared to that of alumina (Figure 12). The total MZ thickness was $2 \mu \mathrm{m}$. The displacement changed slowly during alumina layer thickening, but when the MZ thickness increased from 0 to $2 \mu \mathrm{m}$, as shown in Figure 12, 


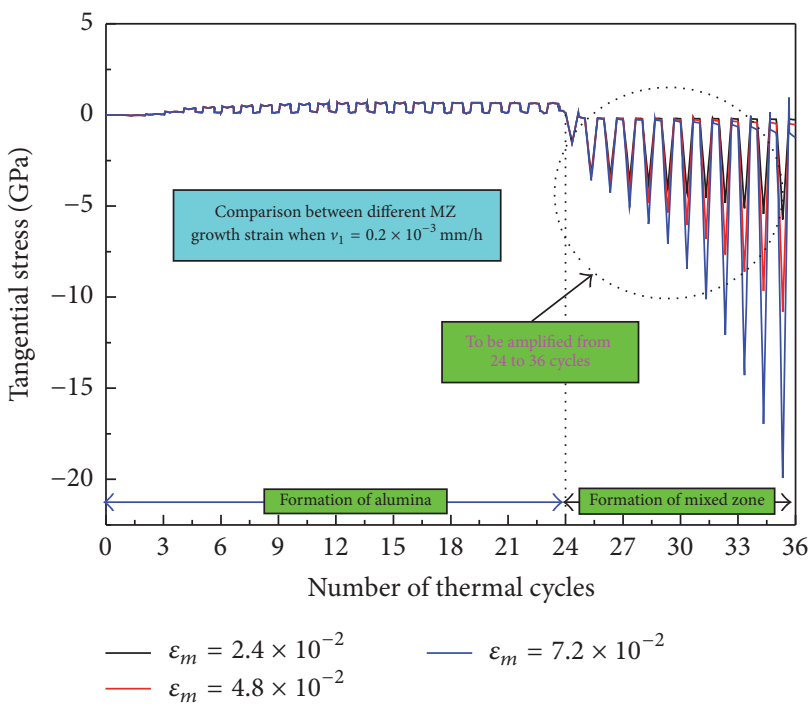

(a)

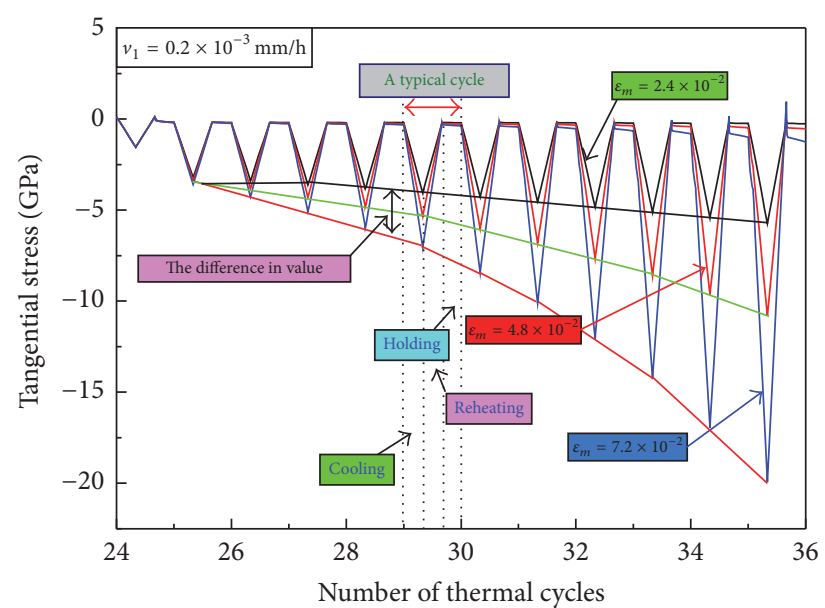

(b)

FIGURE 10: (a) The variation of the tangential stress at element number 20857 at the base of the surface groove against the number of thermal cycles when $v_{1}=0.2 \times 10^{-3} \mathrm{~mm} / \mathrm{h}$. (b) The details for the variation of tangential stress for the first two thermal cycles.

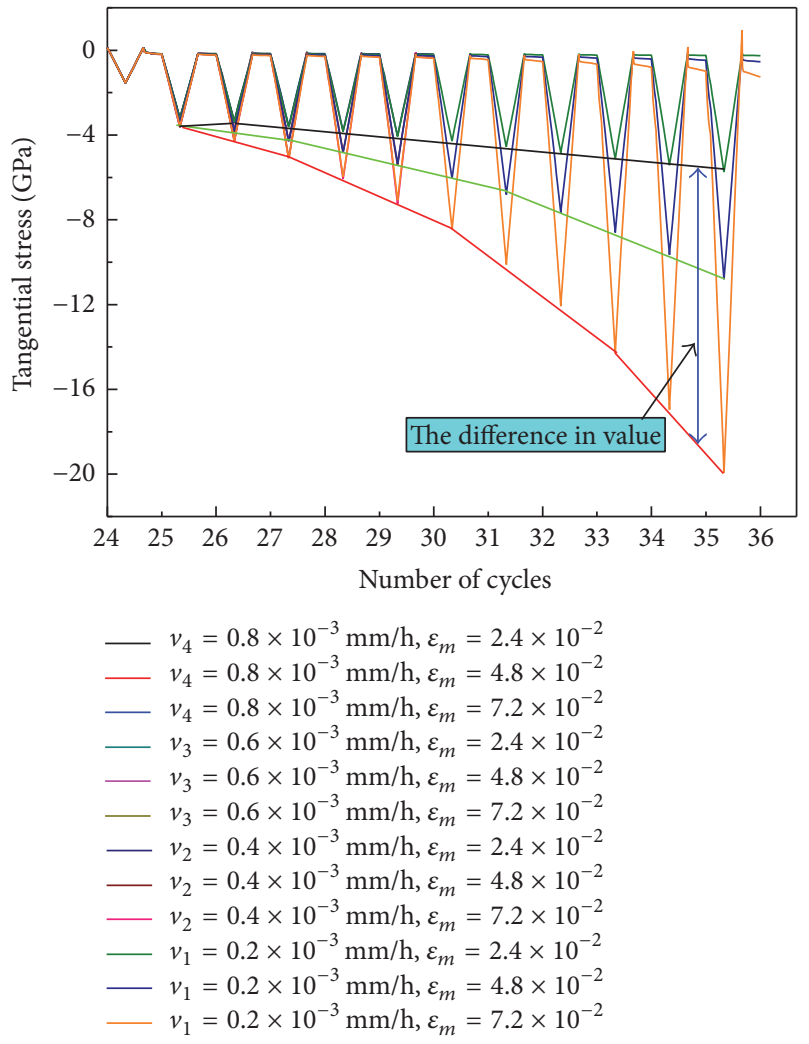

FIGURE 11: The variation of the tangential stress at element number 20857 at the base of the surface groove against the number of thermal cycles for all conditions of MZ growth rate.

the displacement began to change rapidly. When the $\mathrm{MZ}$ thickness was increased further, the trend in increasing displacement was almost linear. Therefore, the thicker the MZ layer, the larger the displacement instability. Furthermore,

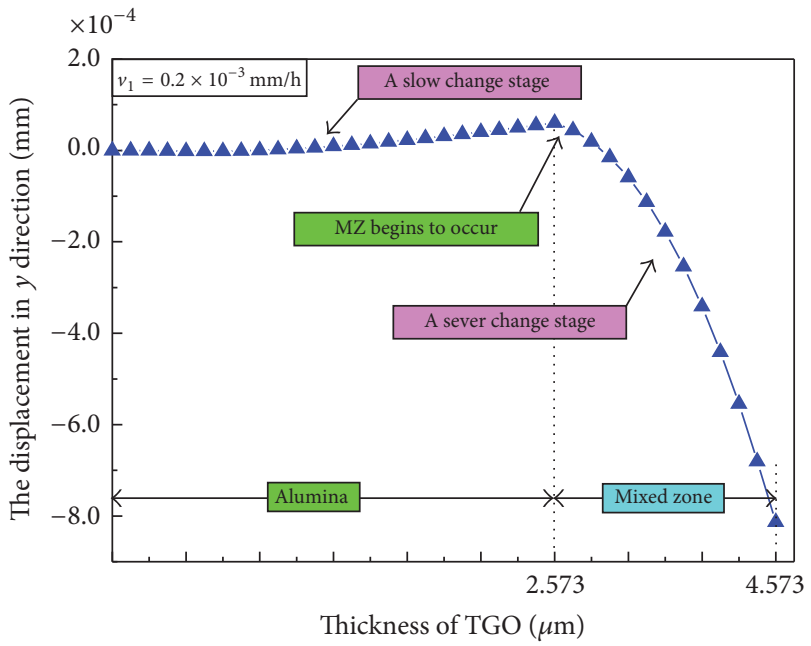

FIGURE 12: The plot of displacement in $y$ direction for node number 517 at the base of the surface groove against the number of thermal cycles.

this trend was observed when the growth rates were $v_{2}=0.4 \times$ $10^{-3} \mathrm{~mm} / \mathrm{h}, v_{3}=0.6 \times 10^{-3} \mathrm{~mm} / \mathrm{h}$, and $v_{4}=0.8 \times 10^{-3} \mathrm{~mm} / \mathrm{h}$ (data not shown).

It is generally accepted that the thickening of TGO will lead to large stresses; this can be observed in Figure 13. The stress increased with the increase in TGO thickness. However, during MZ formation, the stress seemed to accelerate increasing. Stress also followed the two-stage process, with a slowly changing stage caused by the formation of the alumina layer, at which stage there was no MZ layer, followed by a sharply changing stage induced by $\mathrm{MZ}$ formation. The effects of MZ thickness on stress evolution were more significant than those of the alumina layer thickness. Indeed, the stress increased with increasing MZ thickness. Furthermore, this 


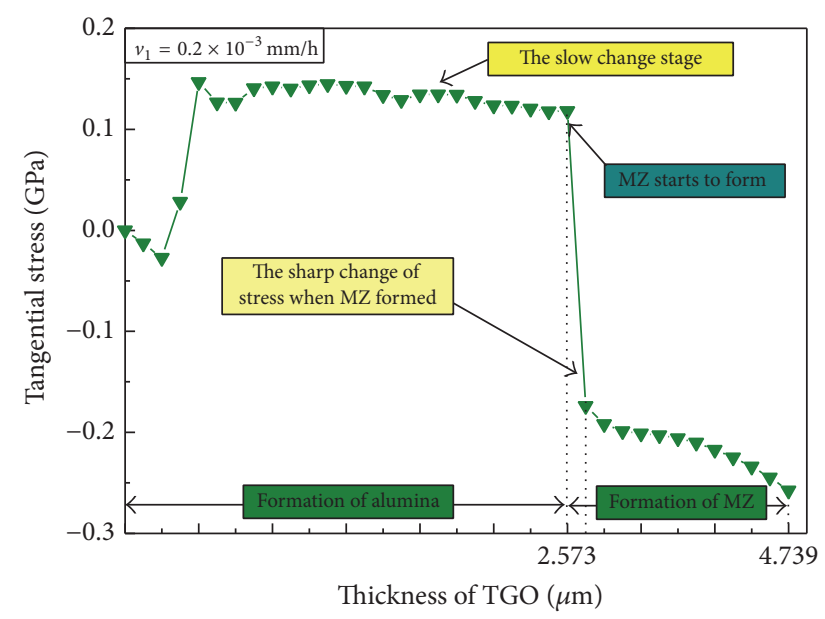

FIGURE 13: Variation of tangential stress at element number 20857 at the base of the surface groove against the number of thermal cycles when $v_{1}=0.2 \times 10^{-3} \mathrm{~mm} / \mathrm{h}$.

can also be observed in the other three conditions, when the growth rates were $v_{2}=0.4 \times 10^{-3} \mathrm{~mm} / \mathrm{h}, v_{3}=0.6 \times 10^{-3} \mathrm{~mm} / \mathrm{h}$, and $v_{4}=0.8 \times 10^{-3} \mathrm{~mm} / \mathrm{h}$ (data not shown).

\section{Conclusions}

The effects of MZ on the displacement instability of TGO were assessed in this paper. The results show that the formation of MZ exerts a significant influence on displacement instability and stress in TGO, leading to an acceleration of TBC failure, which agrees well with the pervious works [14, 15]. Based on the simulation results presented in this work, the following conclusions can be drawn:

(1) The MZ growth rate induces a rapid change of displacement instability and stress in TGO. The displacement instability and stress in TGO increase with the increase in MZ growth rate. The higher the growth rate, the larger the displacement instability and stress.

(2) The growth strain of MZ can result in fast change of displacement instability and stress change in TGO. The increase of MZ growth strain will result in an increase of displacement instability and a huge increasing of stress in TGO. The higher the growth strain is, the higher the displacement instability is and the higher the stress in TGO is.

(3) The thickening of MZ will also lead to a sharp increase in TGO displacement instability and stress. The thicker the MZ layer, the larger the TGO displacement instability and stress.

\section{Nomenclature}

TBC: Thermal barrier coating

TGO: Thermally grown oxide

MZ: Mixed zone

BC: $\quad$ Bond coat
E: Young's modulus

$v$ : Passion ratio

$\varepsilon_{t}:$ TGO normal growth strain

$\varepsilon_{g}:$ TGO lateral growth strain

$\varepsilon_{\mathrm{Al}}$ : Alumina lateral growth strain

$\varepsilon_{m}$ : MZ lateral growth strain.

\section{Competing Interests}

The authors declare no conflict of interests.

\section{Acknowledgments}

This work is financially supported by the Natural Science Foundation of China (11302272) and by NSAF (Grant no. U1530140).

\section{References}

[1] S. Grape, S. Jacobsson Svärd, C. Hellesen, P. Jansson, and M. Åberg Lindell, "New perspectives on nuclear powergeneration IV nuclear energy systems to strengthen nuclear non-proliferation and support nuclear disarmament," Energy Policy, vol. 73, pp. 815-819, 2014.

[2] A Technology Roadmap for Generation IV Nuclear Energy Systems, US DOE Nuclear Energy Research Advisory Committee and the Generation IV International Forum.

[3] L. Wang, D. C. Li, J. S. Yang et al., "Modeling of thermal properties and failure of thermal barrier coatings with the use of finite element methods: a review," Journal of the European Ceramic Society, vol. 36, no. 6, pp. 1313-1331, 2016.

[4] A. G. Evans, D. R. Mumm, J. W. Hutchinson, G. H. Meier, and F. S. Pettit, "Mechanisms controlling the durability of thermal barrier coatings," Progress in Materials Science, vol. 46, no. 5, pp. 505-553, 2001.

[5] S.-W. Myoung, S.-S. Lee, H.-S. Kim et al., "Effect of post heat treatment on thermal durability of thermal barrier coatings in thermal fatigue tests," Surface \& Coatings Technology, vol. 215, pp. 46-51, 2013.

[6] V. Kumar and K. Balasubramanian, "Progress update on failure mechanisms of advanced thermal barrier coatings: a review," Progress in Organic Coatings, vol. 90, pp. 54-82, 2016.

[7] A. M. Karlsson and A. G. Evans, "A numerical model for the cyclic instability of thermally grown oxides in thermal barrier systems," Acta Materialia, vol. 49, no. 10, pp. 1793-1804, 2001.

[8] C. H. Hsueh and E. R. Fuller, "Analytical modeling of oxide thickness effects on residual stresses in thermal barrier coatings," Scripta Materialia, vol. 42, no. 8, pp. 781-787, 2000.

[9] J. Ding, F.-X. Li, and K.-J. Kang, "Effects of material creep on displacement instability in a surface groove under thermomechanical cycling," Surface and Coatings Technology, vol. 204, no. 1-2, pp. 157-164, 2009.

[10] Y. Z. Liu, S. J. Zheng, Y. L. Zhu, H. Wei, and X. L. Ma, "Microstructural evolution at interfaces of thermal barrier coatings during isothermal oxidation," Journal of the European Ceramic Society, vol. 36, no. 7, pp. 1765-1774, 2016.

[11] M. T. Hernandez, A. M. Karlsson, and M. Bartsch, "On TGO creep and the initiation of a class of fatigue cracks in thermal barrier coatings," Surface and Coatings Technology, vol. 203, no. 23, pp. 3549-3558, 2009. 
[12] B. Lv, H. Xie, R. Xu, X. Fan, W. Zhang, and T. J. Wang, "Effects of sintering and mixed oxide growth on the interface cracking of air-plasma-sprayed thermal barrier coating system at high temperature," Applied Surface Science, vol. 360, pp. 461-469, 2016.

[13] R. Xu, X. L. Fan, W. X. Zhang, and T. J. Wang, "Interfacial fracture mechanism associated with mixed oxides growth in thermal barrier coating system," Surface and Coatings Technology, vol. 253, pp. 139-147, 2014.

[14] W. Braue, P. Mechnich, K. Fritscher, and L. Niewolak, "Compatibility of mixed zone constituents (YAG, YAP, $\mathrm{YCrO}_{3}$ ) with a chromia-enriched TGO phase during the late stage of TBC lifetime," Surface and Coatings Technology, vol. 202, no. 4-7, pp. 670-675, 2007.

[15] W. Braue, U. Schulz, K. Fritscher, C. Leyens, and R. Wirth, "Analytical electron microscopy of the mixed zone in NiCoCrAlYbased EB-PVD thermal barrier coatings: as-coated condition versus late stages of TBC lifetime," Materials at High Temperatures, vol. 22, no. 3-4, pp. 393-401, 2005.

[16] Y. Li, C.-J. Li, Q. Zhang, G.-J. Yang, and C.-X. Li, "Influence of TGO composition on the thermal shock lifetime of thermal barrier coatings with cold-sprayed MCrAlY bond coat," Journal of Thermal Spray Technology, vol. 19, no. 1-2, pp. 168-177, 2010.

[17] Y. Bai, C. Ding, H. Li et al., "Isothermal oxidation behavior of supersonic atmospheric plasma-sprayed thermal barrier coating system," Journal of Thermal Spray Technology, vol. 22, no. 7, pp. 1201-1209, 2013.

[18] R. D. Maier, C. M. Scheuermann, and C. W. Andrews, "Degradation of a two-layer thermal barrier coating under thermal cycling," American Ceramic Society Bulletin Journal, vol. 60, pp. 555-560, 1981. 

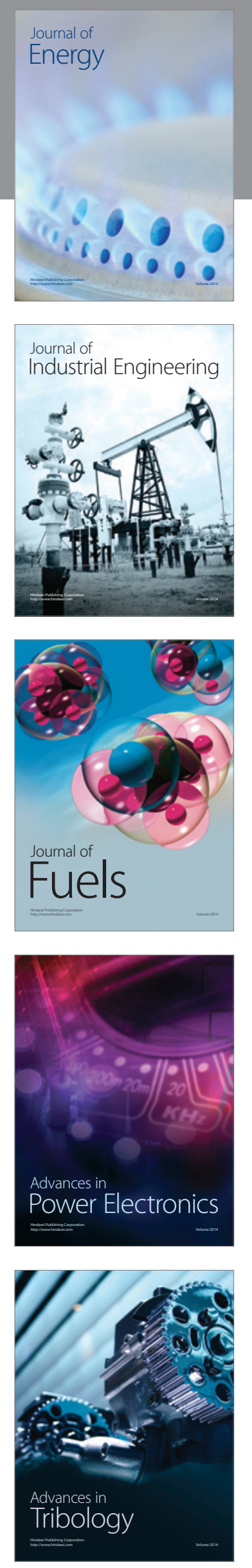
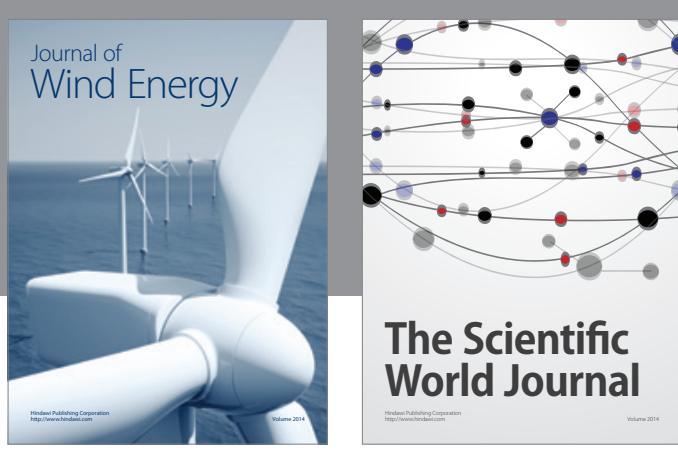

The Scientific World Journal
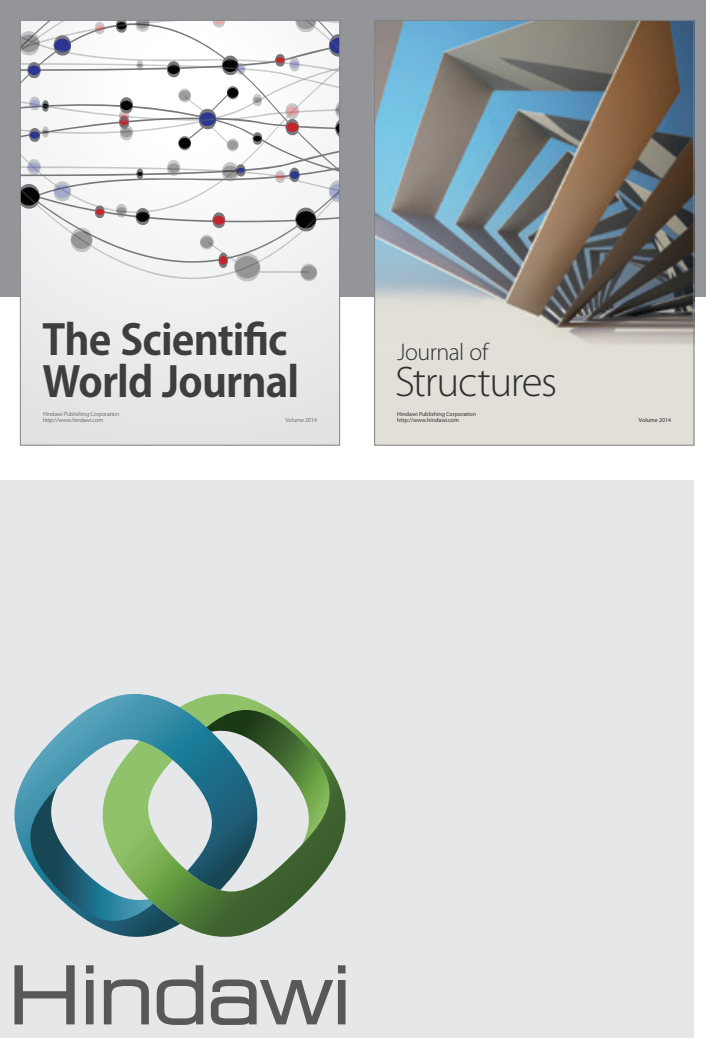

Submit your manuscripts at

http://www.hindawi.com
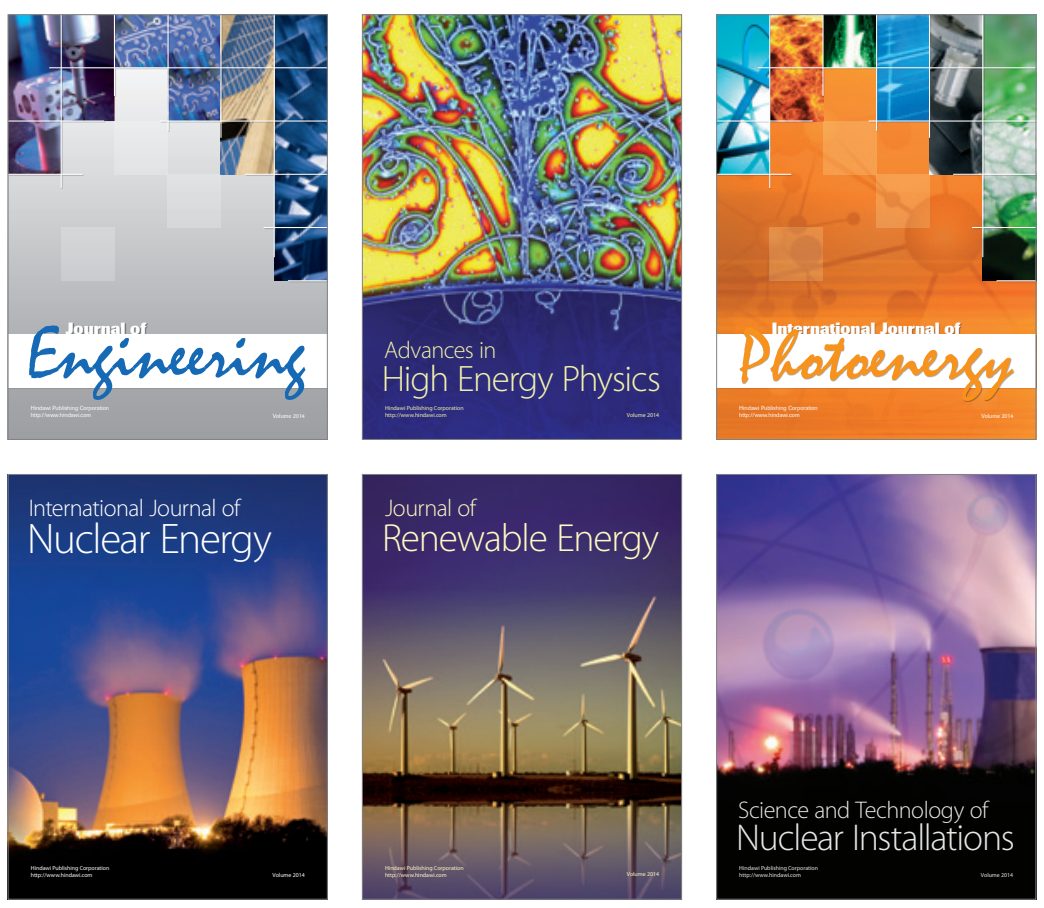
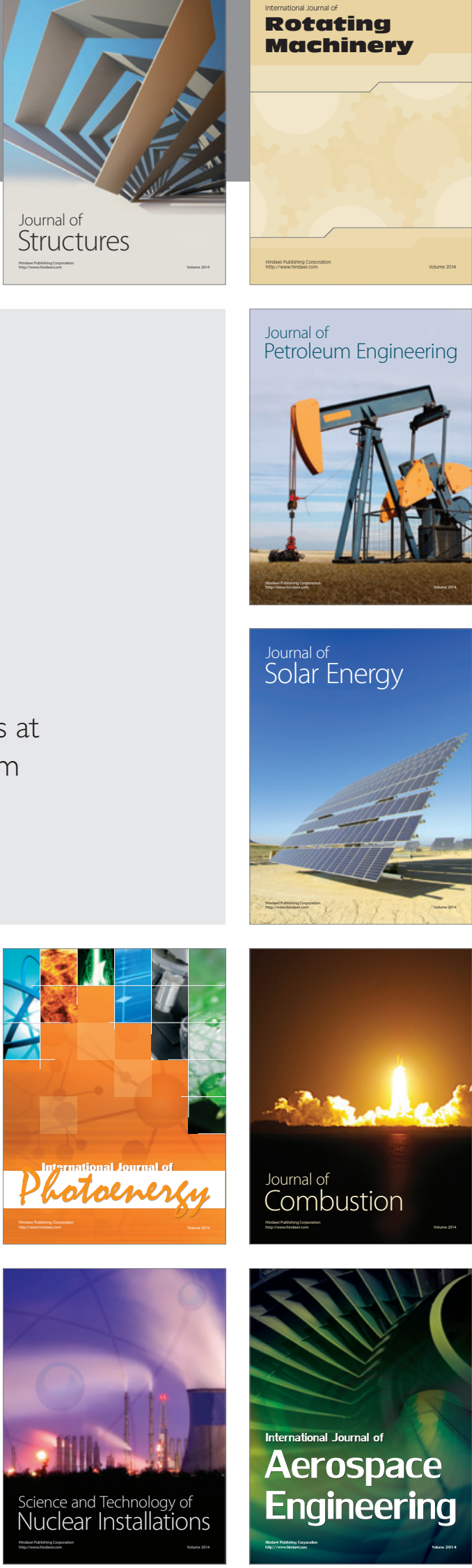